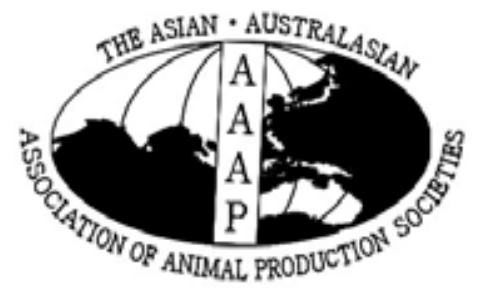

Asian-Aust. J. Anim. Sci.

Vol. 19, No. 9 : 1229 - 1233

September 2006

www.ajas.info

\title{
Candidate Genes with Ovulation by Differential Display PCR in Small Tail Han Sheep*
}

\author{
Liu Shufang ${ }^{1,2}$, Li Hongbin ${ }^{1}$, Song Xuemei ${ }^{1}$, Wang Aihua ${ }^{1}$, Wei Caihong and Du Lixin ${ }^{1, * *}$ \\ ${ }^{1}$ National Center for Molecular Genetics and Breeding of Animal, Institute of Animal Science \\ Chinese Academy of Agricultural Sciences, Beijing 100094, P. R. China
}

\begin{abstract}
To find the candidate genes concerned with ovulation rate of sheep, Differential Display Reverse Transcription Polymerase Chain Reaction was employed to find the differently expressed cDNA controlling ovulation in the Small Tail Han sheep of polyembryony and in Tan sheep of single birth. Twenty-four primer pairs of three anchored primers and eight arbitrary primers were assembled to amplify the specialized bands from these sheep. Positive cross tests were applied to optimize the ascertainable PCR conditions in which different special bands can be identified by silver strain in one PCR tube. After eliminating the false positive PCR products by Northern hybridization, 24 differential display bands were acquired from the ovary in the Small Tail Han sheep. These EST bands were sequenced and 18 different ESTs were found in which five ESTs had several copies and 13 ESTs had only one copy. Comparing these ESTs with homologous sequences by BLAST in the GenBank, there were six ESTs with known open reading frame (ORF) and function, three ESTs with known ORF and no function, and 9 ESTs without homologous sequence. These ESTs partly represent several genes such as NOS2, tensin, TCRA, CDKN1A, ESR1 and ACTB which express especially in Small Tail Han sheep. (Key Words : Ovary, Little Size, Small Tail Han Sheep, DD-PCR)
\end{abstract}

\section{INTRODUCTION}

The Small Tail Han sheep is a celebrated high reproductive sheep line with early mature, perennial oestrus and polyembryony in the world, which come from a ramus of Mongolia sheep. The average lamb rate of breeding ewe are $286.5 \%$ and multiparous ewe are $304.3 \%$ (Du et al., 2003). Tan sheep is another ramus of Mongolia sheep in China characterized by single birth. These sheep lines had kept atretic breeding method since 300 years ago in their respective group from Mongolia sheep line. Therefore, the two sheep line had the similar heredity material except the difference of little size which made it possible to study the molecular mechanism of fetus quality.

Differential Display Reverse Transcription Polymerase

\footnotetext{
* This research is supported by National Nature Science Foundation of China, Project No. 30270949.

** Corresponding Author: Du Lixin. Tel: +86-10-62819997, E-mail: 1xdu@263.net

${ }^{2}$ Key Laboratory for Sustainable Utilization of Marine Fisheries Resources,Ministry of Agriculture, Yellow Sea Fisheries Research Institute, Chinese Academy of Fishery science, Qingdao 266007, P. R. China.
}

Received November 18, 2005; Accepted February 11, 2006
Chain Reaction (DDRT-PCR) is an mRNA fingerprinting technique to identify differentially expressed genes by comparative display of arbitrarily amplified cDNA subsets (Liang et al., 1992). This attractively simple screening method was, however, followed by a labour intensive multistep identification procedure for DD-PCR products.

As an important reproductive organ determining reproductive performance of female animal, ovary has outer excrete function of ovary periodically and inner excrete function of hormone verifies greatly based on the animal species. Thus, it is likely that during the follicles development some other unknown genes are associated in regulation of proliferation and differentiation of ollicle. To better understand the molecular mechanism of this process, the difference of mRNA in mature or small follicles was determined by DDRT-PCR technique in this study.

\section{MATERIALS AND METHODS}

\section{Reagent}

TRIzol Reagent (Gibco BR L, Life Technologies, USA), DEPC (Sigma, MO, USA), Expand TM Reverse Transcriptase (Roche, Basel,Switzerland), PAGE gel 
reclaimed kit (Minipo, France), DIG DNA Labeling and Detection Kit (Roche, Basel, Switzerland).

\section{Primer}

The cDNA primers of three anchored primers of $\mathrm{H}$ T11A, H-T11G and H-T11C and eight arbitrary primers of H-AP17 H-AP24 were designed according to the thirdgeneration primers of GenHunter Company. Anchored primers were :

$$
\begin{aligned}
& \text { H-T }{ }_{11} \mathrm{~A}: \text { 5'-AAGCTTTTTTTTTTTA-3' } \\
& \text { H-T }{ }_{11} \mathrm{G}: \text { 5'-AAGCTTTTTTTTTTTG-3' } \\
& \text { H-T }_{11} \mathrm{C}: \text { 5'-AAGCTTTTTTTTTTTC-3' }
\end{aligned}
$$

Arbitrary primers were :

H-AP17: 5'-AAGCTTACCAGGT-3'

H-AP18: 5'-AAGCTTAGAGGCA-3'

H-AP19: 5'-AAGCTTATCGCTC-3'

H-AP20: 5'-AAGCTTGTTGTGC-3'

H-AP21: 5'-AAGCTTTCTCTGG-3'

H-AP22: 5'-AAGCTTTTGATCC-3'

H-AP23: 5'-AAGCTTGGCTATG-3'

H-AP24: 5'-AAGCTTCACTAGC-3'

\section{Collection of ovarian in the follicular phase}

Ovaries were collected from three healthy euthanized multiparous Small Tail Han ewe which provides by institute of Small Tail Han Sheep of Shandong Province, and three euthanized multiparous Tan ewe which come from Tan Sheep Farm of Ningxia Municipality. These ovaries from all the sheep were at the early stage of oestrus and stored at liquid nitrogen.

\section{Preparation of RNA and reverse transcription}

The ovaries samples were harvested and stored at liquid nitrogen for RNA isolation, ovary which stored in liquid nitrogen were cut out and ground into flour, then extracted by Trizol (GIBCO BRL) according to the manufacturer's instructions. The total RNA samples were purified byOligotex Kit (QIAGEN, Inc, USA) and quantitated by absorbance at $260 \mathrm{~nm}$ and evaluation on formaldehyde gels. For reverse transcription of an mRNA subset, $0.2 \mu \mathrm{g}$ of RNA was mixed first with 50 pmol anchor primer in a volume of $7 \mu \mathrm{l}$, kept for $10 \mathrm{~min}$ at $65^{\circ} \mathrm{C}$ and immediately put on ice. Following addition of $300 \mathrm{U}$ MLV-reverse transcriptase, it was incubated for $1 \mathrm{~h}$ at $37^{\circ} \mathrm{C}$ in reverse transcription buffer $(40 \mathrm{mM} \mathrm{KCl}, 50 \mathrm{mM}$ Tris- $\mathrm{HCl} \mathrm{pH} 8.3$, $6 \mathrm{mM} \mathrm{MgCl}_{2}$ ) containing $20 \mathrm{mM} \mathrm{dNTP,} 10 \mathrm{mM} \mathrm{DTT}$ and $40 \mathrm{U}$ RNA in a total volume of $20 \mu \mathrm{l}$. After $5 \mathrm{~min}$ at $95^{\circ} \mathrm{C}$ the cDNA was stored at $-20^{\circ} \mathrm{C}$ until use in DD-PCR.

\section{DD-PCR}

DD-PCR was performed with $2 \mu \mathrm{l}$ of $20 \mu \mathrm{l}$ cDNA in a Eppendorf thermal cycler 480 using PCR buffer $(10 \mathrm{mM}$
Tris- $\mathrm{HCl} \mathrm{pH} 8.3,50 \mathrm{mM} \mathrm{KCl}), 2.5 \mathrm{U}$ ExTaq DNA Polymerase (Takara Bio Inc, Japan), $1.25 \mathrm{mM} \mathrm{MgCl}_{2}, 4 \mu \mathrm{M}$ dNTP, $2.5 \mu \mathrm{M}$ of the respective downstream anchor primer and $0.5 \mu \mathrm{M}$ of one upstream DD-primer from the 8 arbitrary primers using the following conditions: $5 \mathrm{~min}$ incubation at $95^{\circ} \mathrm{C}$ followed by 40 cycles of $94^{\circ} \mathrm{C}$ for $30 \mathrm{~s}, 40^{\circ} \mathrm{C}$ for 2 $\min$ and $72^{\circ} \mathrm{C}$ for $30 \mathrm{~s}$ and incubated at $72^{\circ} \mathrm{C}$ for $10 \mathrm{~min}$. The PCR products were resolved on a $10 \%$ polyacrylamide gel at $4{ }^{\circ} \mathrm{C}$ with $150 \mathrm{~V}$ for $10-14 \mathrm{~h}$. The gel was fixed and stained by silver stain and then analyzed (Weaver, et al., 1994). The differentially displayed bands were cut out from a wet polyacrylamide gel. The DNA was eluted and purified with the QIAGEN Gel Extraction Kit (QIAGEN) according to the protocol of the supplier. With $6 \mu \mathrm{l}$ of the $20 \mu \mathrm{l}$ eluation the DD-PCR was repeated as before. The reamplification product was resolved on a $2 \%$ TBE agarose gel, stained with ethidium bromide, recovered with the QIAGEN Gel Extraction Kit and resuspended in $20 \mu \mathrm{l}$ $\mathrm{ddH}_{2} \mathrm{O}$. This amplification was used for (i) direct sequencing and (ii) generation of a labeled probe.

\section{Reverse northern}

The reverse Northern test was performed using a transcription as probe labeled by ovary RNA extracted from Small Tail Han sheep or Tan sheep according to the kit manuscript. Briefly, the differential bands of Tan or Han sheep were resolved by $6 \times \mathrm{SSC}$ and diluted to $50 \mu \mathrm{g} / \mu \mathrm{l}$. Each sample was dotted in the same location on two nylon membranes .The genome of Tan and Han sheep were used as positive and $6 \times \mathrm{SSC}$ solution as negative. After denaturalization, neutralization, desiccation and torrefaction, the nylon membranes were hybridized with probes labeled with the first cDNA strand of Tan or Han sheep at $68^{\circ} \mathrm{C}$ a night. On next day the membranes were washed and added into antibody and its substrate to inspect the results at room temperature.

\section{Sequence and analysis of differential bands}

The recovered differential bands were ligated with pGEM-T easy vector and transfermated to complement cells of DH5 $\alpha$. The positive clones were sequenced by Boya CTD and analyzed by BLAST in GenBank.

Some software of BLASTn and FASTA3.1 were operated on these sequences with GenBank and EMBL. If the score of BLASTn overcome than 100, the E value of ESTs was less than 1e-10 and the identity overran $90 \%$, we contributed these sequences as one family (Table 1). To forecast the open reading frame (ORF), these sequences were screened by GenScan (http://genes.mit.edu/ GENSCAN.html) to acquire the possible nucleotide and amino acid sequence. Those sequences which score outcome than 100 will annotated on its function. 
Table 1. Differential expression genes database of DDRT-PCR between ovaries in Small Tail Han Sheep and Tan Sheep

\begin{tabular}{|c|c|c|c|c|c|c|c|c|}
\hline Name & GenBank ID & bp & Copies & BLASTn homologous sequence & Function & Score & E value & Identities \\
\hline$\overline{\mathrm{O} 05^{1}}$ & $\mathrm{C} 0001054$ & 104 & 2 & & Unknown gene & & & \\
\hline $\mathrm{O} 08$ & $\mathrm{C} 0001055$ & 245 & 1 & & Unknown gene & & & \\
\hline $\mathrm{O} 10$ & $\mathrm{C} 0001056$ & 187 & 1 & $\begin{array}{l}\text { gi } 21637524|\mathrm{gb}| \mathrm{AC} 091133.11 \mid \\
\text { Length }=68613\end{array}$ & $\begin{array}{l}\text { Homo sapiens chromosome 17, clone RP11- } \\
501 \mathrm{C} 14\end{array}$ & 168 & $2 \mathrm{e}-39$ & $\begin{array}{l}128 / 141 \\
(90 \%)\end{array}$ \\
\hline $\mathrm{O} 13$ & & 113 & 2 & $\begin{array}{l}\text { gi }|25992264| \mathrm{gb} \mid \text { AF520959.1| } \\
\text { Length }=482\end{array}$ & $\begin{array}{l}\text { Bos taurus ubiquitin-like/S30 ribosomal } \\
\text { fusion protein }\end{array}$ & 174 & $2 \mathrm{e}-41$ & $\begin{array}{r}91 / 92 \\
(98 \%)\end{array}$ \\
\hline O14 & $\mathrm{C} 0001057$ & 373 & 1 & & Unknown gene & & & \\
\hline $\mathrm{O} 21$ & $\mathrm{C} 0001058$ & 428 & 1 & $\begin{array}{l}\text { gi|13383951|gb|AF333248.1|AF333248 } \\
\text { Length=8504 }\end{array}$ & $\begin{array}{l}\text { Bos taurus inducible nitric oxide synthase } \\
\text { (NOS2) gene }\end{array}$ & 71.9 & $9 \mathrm{e}-10$ & $\begin{array}{l}132 / 164 \\
(80 \%)\end{array}$ \\
\hline $\mathrm{O} 26^{2}$ & $\mathrm{C} 0001059$ & 326 & 3 & $\begin{array}{l}\text { gi|11275670|gb|AF225897.1|AF225897 } \\
\text { Length }=7164\end{array}$ & Bos taurus tensin mRNA & 377 & e-102 & $\begin{array}{l}255 / 273 \\
(93 \%)\end{array}$ \\
\hline $\mathrm{O} 32$ & $\mathrm{C} 0001060$ & 108 & 1 & $\begin{array}{l}\text { gi }|28403988| \mathrm{gb}|\mathrm{AY} 227782.1| \\
\text { Length }=97500\end{array}$ & $\begin{array}{l}\text { Bos taurus } \mathrm{T} \text { cell receptor alpha (TCRA) } \\
\text { gene }\end{array}$ & 87.7 & $3 e-15$ & $\begin{array}{r}71 / 80 \\
(88 \%)\end{array}$ \\
\hline $\mathrm{O} 34$ & $\mathrm{C} 0001061$ & 146 & 2 & $\begin{array}{l}\text { gi|26097379|dbj|AK077497.1| } \\
\text { Length }=3014\end{array}$ & $\begin{array}{l}\text { Mus musculus } 8 \text { days embryo whole body } \\
\text { cDNA, RIKEN full-length enriched library, } \\
\text { clone: } 5730422 \mathrm{C} 08 \text {, product: p21 } \\
\text { (CDKN1A)-activated kinase } 1\end{array}$ & 87.7 & $5 e-15$ & $\begin{array}{l}102 / 120 \\
(85 \%)\end{array}$ \\
\hline $\mathrm{O} 36$ & $\mathrm{C} 0001062$ & 194 & 1 & & Unknown gene & & & \\
\hline $\mathrm{O} 37^{3}$ & $\mathrm{C} 0001063$ & 201 & 2 & & Unknown gene & & & \\
\hline O39 & $\mathrm{C} 0001064$ & 290 & 1 & & Unknown gene & & & \\
\hline $\mathrm{O} 42$ & $\mathrm{C} 0001065$ & 177 & 1 & & Unknown gene & & & \\
\hline $\mathrm{O} 43$ & $\mathrm{C} 0001066$ & 401 & 1 & $\begin{array}{l}\text { gi|37499470|gb|AY425004.1| } \\
\text { Length=299637 }\end{array}$ & $\begin{array}{l}\text { Homo sapiens estrogen receptor } 1 \text { (ESR1) } \\
\text { gene }\end{array}$ & 77.8 & $1 \mathrm{e}-11$ & $\begin{array}{r}70 / 79 \\
(88 \%)\end{array}$ \\
\hline $\mathrm{O} 44$ & $\mathrm{C} 0001067$ & 178 & 1 & $\begin{array}{l}\text { gi|28189253|dbj|AB098782.1| } \\
\text { Length }=700\end{array}$ & $\begin{array}{l}\text { Bos taurus mRNA for similar to tumor } \\
\text { protein, translationally-controlled } 1\end{array}$ & 278 & $3 e-72$ & $\begin{array}{l}153 / 156 \\
(98 \%)\end{array}$ \\
\hline $\mathrm{O} 45$ & $\mathrm{C} 0001068$ & 182 & 1 & $\begin{array}{l}\text { gi|33504457|emb|Z86064.2|HS435D1 } \\
\text { Length }=184975\end{array}$ & $\begin{array}{l}\text { Human DNA sequence from clone RP3- } \\
435 \mathrm{D} 1 \text { on chromosome } \mathrm{Xq} 25\end{array}$ & 95.6 & $3 e-17$ & $\begin{array}{r}81 / 92 \\
(88 \%)\end{array}$ \\
\hline O46 & $\mathrm{C} 0001069$ & 246 & 1 & & Unknown gene & & & \\
\hline $\mathrm{O} 48$ & $\mathrm{C} 0001070$ & 118 & 1 & $\begin{array}{l}\text { gi| } 22655315|\mathrm{gb}| \mathrm{AY} 141970.1 \mid \\
\text { Length }=1804\end{array}$ & Bos taurus beta-actin (ACTB) mRNA & 155 & $2 \mathrm{e}-35$ & $\begin{array}{r}87 / 90 \\
(96 \%)\end{array}$ \\
\hline
\end{tabular}

${ }^{1} \mathrm{O} 05$ sequence of EST same as O06. ${ }^{2} \mathrm{O} 26$ sequence of EST same as $\mathrm{O} 28, \mathrm{O} 41 .{ }^{3} \mathrm{O} 37$ sequence of EST same as O38.

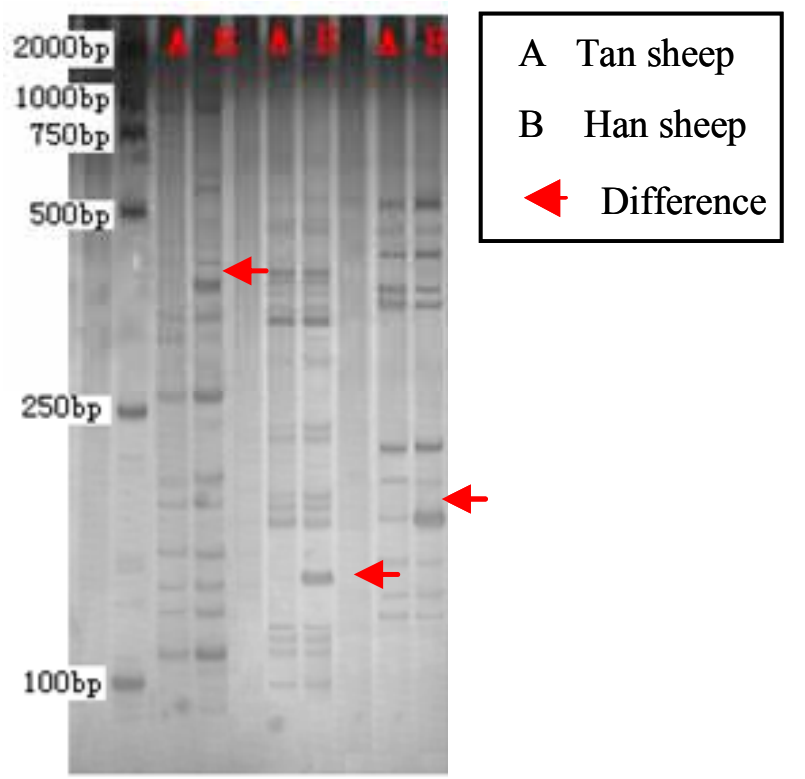

Figure 1. Polyacrylamide gel electrophoresis of DDRT-PCR (partial).

\section{RESULTS}

Extraction and reverse transcription of total RNA of

\section{sheep ovary}

High quality RNA was found to be imperative for the success of the subsequent steps. To stabilize the similarity of Tan and Han sheep, we collected the ovary at the same follicles phages to extract RNA. The gel profile of RNA showed two clarity bands of $28 \mathrm{~S}$ and $18 \mathrm{~S}$ which were accord with the requirement of reverse transcription. These RNA were used as template to transcript for next step of DD-PCR.

\section{Ovary DD-PCR of Tan and Han sheep}

To optimize the differential display condition of Tan and Han sheep ovary, we performed 3 anchored primers and 8 arbitrary primers comprising of 24 pairs to react with two different kinds of RNA. Most of bands centralized at $100 \mathrm{bp}$ to $1,000 \mathrm{bp}$. Experimental group of Han sheep as template got 632 bands while Tan sheep as template got 589 bands (Figure 1). At last 54 bands were choosen to recover and sequence according to the lack, density and size from both Han and Tan sheep ovary.

The recovered differential bands were reamplificated with the same anchor primer and arbitraryprimer using recovered products as template. However, some of bands (6/54) couldn't amplify the same size band as before. Other bands ranged from $200 \mathrm{bp}$ to $1,000 \mathrm{bp}$. 
(A)

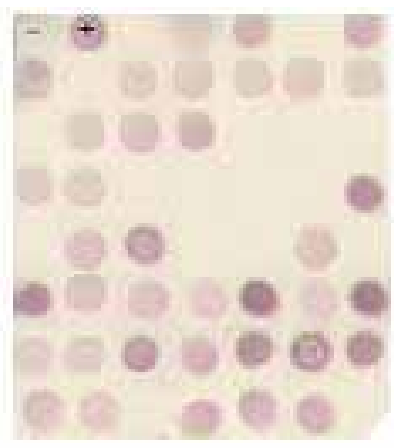

(B)

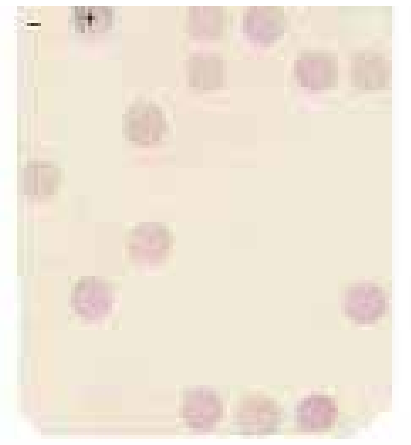

Figure 2. Detection of different samples with cDNA probe of the ovary. (A) Small Tail Han Sheep, (B) Tan sheep.

\section{Reverse northern}

In order to eliminate the disruption of error positive samples, reverse northern were carried out to validate differential bands. Fifty-four differential bands of PCR amplifications were blotted on two nylon membranes and hybridized with probes of Han ovary or Tan ovary. The results shown that a membrane had 37 positive blot hybridized with Han ovary probe while the other membrane had 13 positive blot hybridized with Tan ovary probe (Figure 2). Based on the origin of these differential bands which derived from Tan or Han sheep ovary, 24 bands were special expression genes in Small Tail Han sheep ovary while other bands were expressed both in Han and Tan sheep ovary.

\section{Sequence and analysis of differential bands}

The 23 positive bands of Small Tail Han sheep ovary were cloned and sequences. It was obvious that these sequences were ESTs ranged from $100 \mathrm{bp}$ to $500 \mathrm{bp}$ and the ratio of $100 \mathrm{bp}$ to $200 \mathrm{bp}$ bands was $54.2 \%$. When found these positive bands of Han sheep ovary, we wanted to assess the background of these sequences. Table 1 demonstrated that 5 ESTs have several copies and 13 ESTs have only one copy among 24 different ESTs. Comparing these ESTs with homologous sequences by BLAST in the GenBank, there are 6 ESTs with known ORF and function, 3 ESTs with known ORF and un-function, and 9 ESTs without homologous sequence. And these ESTs are the part represent of several genes such as NOS2 (Bayir $\mathrm{H}$, et al., 2005), tensin (Sanchez et al., 2005), TCRA (Ramiro, et al., 2001), CDKN1A (Rishi et al., 1997), ESR1 (Kato et al., 1994) and ACTB (Dahlen et al., 2004) which display specially in Small Tail Han sheep.

\section{DISCUSSION}

In this experiment, the primers were the third generation
DDRT-PCR primers which both anchored and arbitrary primers have Hind enzyme site. The number of primers also reduces to three anchored primers and eight arbitrary primers, while the number of bases increases to 16 and13. This primer recombination had proved by computer analysis to have the ability to include all mRNAs in certain stage of some cell development which make it easier to next operation and treatment.

However, it is obvious that the high sensitivity of DDRT-PCR will increase problems such as high background, low reproducibility and very high proportion of false positives. According to the published results and personal communications, it appeared to be a common problem. In avoid of these problems, all the RNA samples were treat ed with DNase I in our study and the RNA template of reverse transcription should outrun $3 \mu \mathrm{g}$. In order to reduce the disturbances of error positive bands, all the positives from Han sheep ovary were confirmed by reverse Northern which only 24 bands proved to be true. The reverse Northern assay also save a lot of outlay and time for its need of two cDNA probes compared to classical Northern blot assay.

The length of ESTs ranged from $100 \mathrm{bp}$ to $500 \mathrm{bp}$ lied at the 3' UTR which could distinguish the different genes in one gene family. More researches had proved that the length of $150 \mathrm{bp}$ to $400 \mathrm{bp}$ had available information of cDNA identification and chromosome location. Although our ESTs may not include intact ORF of some gene, it represent the gene expression profiles of some cells or organs in certain stages.

In this study, we have acquired 24 differential ESTs expressed in the ovary of the Small Tail Han sheep. Comparing these ESTs with homologous sequences by BLAST in the GenBank, there are six ESTs with known ORF and function, threeESTs with known ORF and unfunction, and nine ESTs without homologous sequence. These known ESTs are the part represent of several genes such as NOS2, tensin, TCRA, CDKN1A, ESR1 and ACTB which display specially in Small Tail Han sheep. The relationships between these genes and sheep reproduction trait did not arouse up attention except ESR1 gene. Our studies further demonstrated that ESR gene may have a great effect on little size. Furthermore, the selected genes by differential display need to be studied and would promote the research of candidate genes which affected high ovulation of Small Tail Han sheep.

\section{REFERENCES}

Bayir, H. H., V. E. Kagan, G. G. Borisenko, Y. Y. TYurina, K. Janesko, V. A. Vagni, T. R. Billiar, D. L. Williams and P. M. Kochanek. 2005. Enhanced oxidative stress in iNOS-deficient mice after traumatic brain injury: support for a neuroprotective 
role of iNOS. J. Cereb Blood Flow Metab. 25:673-684.

Bhatia, S. and R. Arora 2005. Biodiversity and Conservation of Indian sheep genetic resources. - An Overview - Asian-Aust. J. Anim. Sci. 18(10):1387-1402.

Chu, M. X., J. Z. Wang, A. G. Wang, N. Li and J. L. Fu. 2003. Association analysis between five microsatellite loci and litter size in small Tail Han sheep. Asian-Aust. J. Anim. Sci. 16:1555-1559.

Dahlen, A., C. D. Fletcher, F. Mertens, J. A. Fletcher, A. R. PerezAtayde, M. J. Hicks, Debiec-RYchterM, R. Sciot, Wejde, R. Welin, Mandahln, Panagopoulos 1. 2004. Activation of the GLI oncogene through fusion with the beta-actin gene (ACTB) in a group of distinctive pericytic neoplasms: pericytoma with $\mathrm{t}(7 ; 12)$. Am. J. Pathol. May 164:1645-1653.

Doss, R. P. 1996.Differential display without radioactivity a modified procedure. Bio. Techniq. 21: 410-412.

Du, Lixin and Cao Dingguo. 2003. Genetic Analysis on Littletailed Han Sheep by Microsatellite and RAPD Markers, ACTA Genetica Sinica. 30:1041-1044.

Guo, W. M., X. Chu, X. M. Deng, J. D. Feng, Ning Li and Changxin Wu. 2004. Association of a single codon deletion in bone morphogenetic protein 15 gene with prolificacy in small tail Han sheep. Asian-Aust. J. Anim. Sci. 17(11):1491-1501.

Jia, Cunling, Ning Li, Xingbo Zhao, Xiaoping Zhu and Zhihai Jia. 2005. Association of single nucleotide polymorphisms in exon 6 region of BMPRIB gene with litter size traits in sheep. Asian-Aust. J. Anim. Sci. 18(10):1375-1378.
Kato, R. and H. Ogawa. 1994. An essential gene, ESR1, is required for mitotic cell growth, DNA repair and meiotic recombination in Saccharomyces cerevisiae. Nucleic Acids Res. 22:3104-3112.

Ramiro, A. R., M. N. Navarro, A. Carreira, Y. R. Carrasco, V. G. de Yebenes, G. Carrillo, J. L. San Millan, B. Rubin and M. L. Toribio. 2001 .Differential developmental regulation and functional effects on pre-TCR surface expression of human pTalpha(a) and pTalpha(b) spliced isoforms. J. Immunol. 167:5106-5114.

Rishi, A. K., C. K. Hsu, X. S. Li, A. Hussain, T. M. Gerald and J. A. Fontana. 1997. Transcriptional repression of the cyclindependent kinase inhibitor p21WAF1/CIP1 gene mediated by cis elements present in the 3 '-untranslated region. Cancer Res. 57:5129-5136.

Sambrook, J., E. F. Fritsch and T. Maniatis. 1989. Molecular Cloning: A Laboratory Manual, Second Edition (Cold Spring Harbor Laboratory Press, Cold Spring Harbor, NY).

Sanchez, T., S. Thangada, M. T. Wu, C. D. Kontos, D. Wu, H. Wu and T. Hla. 2005. PTEN as an effector in the signaling of antimigratory G protein-coupled receptor. Proc. Natl. Acad. Sci. USA. 102:4312-4317.

Sharma, R. C., A. L. Arora, A. K. Mishra, S. Kumar and V. K. Singh. 2004. Breeding prolific garole with malpura sheep for increased reproductive efficiency in semi arid tropics of India. Asian-Aust. J. Anim. Sci. 17(6):737-742.

Weaver, K. R., G. Caetano-Anolles, P. M. Gresshoff and L. M. Callahan. 1994. Isolation and cloning of DNA amplification products from silver stained polyacrylamide gels. Bio. Techniq. 16: $226-230$. 